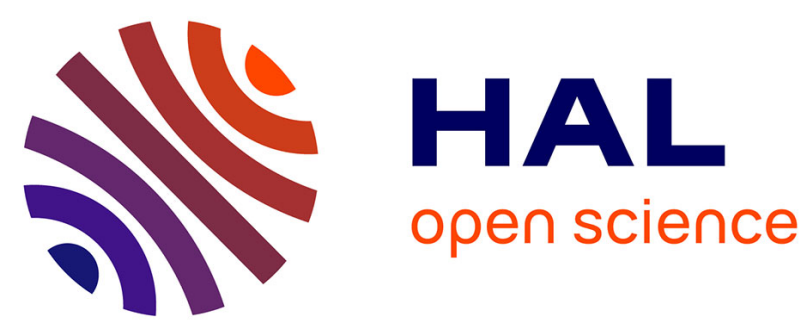

\title{
HIGH-CYCLE FATIGUE BEHAVIOUR OF SPHEROIDAL GRAPHITE CAST IRON
}

H Yaacoub Agha, A.-S. Beranger, R. Billardon, François Hild

\section{To cite this version:}

H Yaacoub Agha, A.-S. Beranger, R. Billardon, François Hild. HIGH-CYCLE FATIGUE BEHAVIOUR OF SPHEROIDAL GRAPHITE CAST IRON. Fatigue and Fracture of Engineering Materials and Structures, 1998, 21 (3), pp.287-296. 10.1046/j.1460-2695.1998.00293.x . hal-02342787

\section{HAL Id: hal-02342787 \\ https://hal.science/hal-02342787}

Submitted on 4 Nov 2019

HAL is a multi-disciplinary open access archive for the deposit and dissemination of scientific research documents, whether they are published or not. The documents may come from teaching and research institutions in France or abroad, or from public or private research centers.
L'archive ouverte pluridisciplinaire HAL, est destinée au dépôt et à la diffusion de documents scientifiques de niveau recherche, publiés ou non, émanant des établissements d'enseignement et de recherche français ou étrangers, des laboratoires publics ou privés. 


\title{
HIGH-CYCLE FATIGUE BEHAVIOUR OF SPHEROIDAL GRAPHITE CAST IRON
}

\author{
H. YaAcoub Agha ${ }^{1}$, A.-S. Béranger ${ }^{2}$, R. Billardon ${ }^{1}$ and F. Hild ${ }^{1}$ \\ ${ }^{1}$ Laboratoire de Mécanique et Technologie, E.N.S. de Cachan, C.N.R.S., Université Paris 6, 61, avenue du Président Wilson, \\ F-94235, Cachan Cedex, France \\ ${ }^{2}$ Renault, Direction de la Recherche, Service 60152, 860, quai de Stalingrad, F-92109 Boulogne Billancourt Cedex, France
}

\begin{abstract}
An expression for the cumulative failure probability of a structure is proposed for cyclic loading conditions. This expression is dependent on an initial flaw distribution and a microcrack propagation law. Two sets of experiments were carried out on specimens made of spheroidal graphite cast iron. These specimens are tested under cyclic tension with two different load ratios. The initial flaw distribution is experimentally identified from microscopic observations. The crack propagation law parameters are identified from experimental results obtained with a load ratio $R=0.1$. The expression for the failure probability is then used to predict experimental data obtained with a load ratio $R=-1$.

Keywords-Probabilistic approach; Initial defects; Cast iron; High-cycle fatigue.
\end{abstract}

\section{NOMENCLATURE}

$a, a_{\mathrm{c}}=$ flaw size, and critical flaw size

$a_{\mathrm{c} 0}=$ initial flaw size that becomes critical after $N_{\mathrm{F}}$ cycles

$a_{\mathrm{M}}, a_{\mathrm{th}}=$ maximum and threshold flaw size, respectively

$b=$ constant

$B_{\alpha \beta}=$ Euler function of the first kind

$C, C^{*}, k, m, n=$ parameters of the crack propagation law

Err $=$ error

$f, f_{0}=$ flaw size and initial flaw size distribution

$g=$ function

$\mathrm{HV}_{30}=$ hardness

$K_{\mathrm{c}}, K_{\mathrm{th}}=$ critical and threshold stress intensity factors

$K_{\max }, K_{\min }=$ maximum and minimum stress intensity factors

$K_{\mathrm{pp}}=$ opening stress intensity factor

$n_{\mathrm{e}}=$ number of experiments

$N, N_{\mathrm{F}}=$ number of cycles (to failure)

$N_{\mathrm{Fje}}, N_{\mathrm{Fi}}=$ experimental and predicted number of cycles to failure

$P_{F}, P_{\mathrm{F} 0}=$ cumulative failure probability of a structure and an element

$R=$ load ratio $\left(=K_{\min } / K_{\max }\right)$

$S_{\text {th }}=$ threshold stress

$x, x_{t h}=$ dimensionless and normalized threshold flaw size, respectively

$V, V_{0}=$ volumes of a structure and an element

$Y=$ dimensionless parameter

$\alpha, \beta=$ parameters of a beta function

$\varphi=$ function

$\sigma=$ uniaxial equivalent stress (e.g. maximum principal stress)

$\sigma_{\max }=$ maximum equivalent stress

$\sigma_{\mathrm{u}}, \sigma_{\mathrm{y} 0.2 \%}=$ ultimate and yield stress

$\sigma_{\infty}=$ fatigue limit 


\section{INTRODUCTION}

Due to its good properties, Spheroidal Graphite (SG) cast iron is widely used in the automotive industry, in particular for safety components. For example, it is utilized in ground link elements, e.g. steering knuckle holder, suspension arms [1]. These cast components are frequently subjected to high-cycle fatigue conditions. The fatigue strength of components may be reduced by the presence of initial casting flaws randomly distributed within the material. Consequently, a life prediction method that accurately evaluates the effect of these casting flaws is required.

To study the fatigue failure of these materials, one needs information about the initial distribution of flaws and their evolution features. The fatigue process in materials can be schematically divided into two stages. Microcrack propagation, which is often due to initial flaws, has to be considered for both brittle and ductile materials. Macrocrack propagation is usually unstable for brittle materials (e.g. engineering ceramics), while first stable and then unstable for ductile materials (e.g. many metals in the domain of low-cycle fatigue). In this paper, we will focus our attention on SG cast iron subjected to high-cycle fatigue. The structure is therefore assumed to remain macroscopically elastic, whereas the microscopic evolution of the flaws is described according to a generalized Paris' law up to local failure. Macroscopic initiation corresponds to local failure and macrocrack propagation is not considered in this paper.

Probabilistic methods applied to predicting failure under monotonic conditions have been extensively used. The first attempt was made by Weibull [2] and was based upon a probabilistic treatment of failure. Monotonic and cyclic loading conditions were analysed. Batdorf and Crose [3] modelled initial flaws by cracks whose sizes and orientations are randomly distributed. Evans and Lamon [4-6] derived another model based upon similar assumptions. Attempts to model stable crack growth have been made by Sobczyk [7] by using stochastic crack growth equations. In the framework of Linear Elastic Fracture Mechanics, Jayatilaka and Trustrum [8] showed that under some simple assumptions, the Weibull parameters can be related to flaw distribution features. These results have been extended in the framework of Linear Elastic Fracture Mechanics and Continuum Damage Mechanics [9]. An expression for the cumulative failure probability was obtained, in which the flaw distribution was directly considered.

The aim of this paper is to apply the latter approach to the analysis of the failure of a ferritic SG cast iron by taking into consideration the initial flaw distribution. On the one hand, it is assumed that the defects are the only initiation sites, so that discussing the Stage I process is irrelevant in the present study. On the other hand, the Stage II phase is referred to as microcrack propagation, as opposed to macrocrack propagation, which corresponds to the minor part of the component life in high-cycle fatigue. The flaw size distribution can be obtained from SEM observations coupled with image analysis. The crack propagation law can be obtained from conventional crack propagation experiments. In the first part of this paper, the crack propagation law is discussed with respect to the considered defects. The second part is concerned with an expression for the cumulative failure probability of a structure subjected to high-cycle fatigue. The third part deals with the analysis of uniaxial tensile tests performed on SG cast iron containing initial casting defects.

\section{MICROCRACK PROPAGATION IN HICH-CYCLE FATIGUE}

In some heterogeneous materials, initial heterogeneities are mostly sphere-like cavities (e.g. intrinsic flaws in ceramics due to processing, flaws due to cooling down in SG cast iron), or spherelike brittle inclusions with low interfacial strength (e.g. graphite in cast iron). Under high-cycle 
fatigue loadings, penny-shaped cracks propagate radially from these heterogeneities. As a first approximation, it is assumed that during microcrack propagation the surface of the defect increases with no morphological change. Therefore, the radius $a$ of the surface is the only parameter to be accounted for, and the microcrack propagation law will be written in terms of this parameter.

A number of studies has been focused on the crack propagation law. They show that short cracks tend to propagate faster than long cracks [10]. Furthermore, a crack arrest phenomenon was observed when specimens were tested below the endurance limit [11]. Experiments clearly showed that the propagation rate of artificial short cracks was larger than the value determined for long cracks [12]. In SG cast iron, there are four different defect populations that may lead to high-cycle fatigue failure. First, pinholes are located at or close to the as-cast surface. These defects were not present in the experiments discussed herein since the studied batch of specimens was machined. Second, graphite nodules [Fig. 1(a)], especially when their geometry degenerates close to the as-cast surface, are potential initiation sites. Again the latter are not considered herein. Third, macro-shrinkage defects $(a>0.5 \mathrm{~mm})$ are routinely detected visually or by NDE techniques, and therefore are not present in the cast components used by the automotive industry. Fourth, microshrinkage porosities $(a \leqslant 0.5 \mathrm{~mm})$ are more difficult to detect and may be present in the components [Fig. 1(b)]. The last class of defects is studied in this paper since they tend to be the micropropagation sites leading to final fracture. Their minimum size is generally greater than that of the graphite nodules (whose maximum size is of the order of a few tens of $\mu \mathrm{m}$ in radius).

The flaws are supposed to be described by cracks whose geometry is taken into account by a dimensionless factor $Y$, such that a general stress intensity factor $K$ is given by

$$
K=Y \sigma \sqrt{a}
$$

In this paper, only proportional loading conditions are considered (i.e. the principal directions are independent of the number of cycles) and bifurcation of the crack is not considered. In the case of non-proportional loading conditions, the previous hypotheses need to be re-visited. It is worth noting that the values of the parameter $Y$ depend upon the geometry of the initial defect and the fact that this flaw intersects, or not, a free surface. For instance, the distance of the flaws to the surface of the structure may be taken into account through the dimensionless parameter $Y$.

To take into account the localized non-linear behaviour of the material in the vicinity of the crack tip under cyclic loading conditions, Elber [13] has shown that crack propagation depends upon a so-called effective stress intensity factor $\Delta K_{\mathrm{eff}}=K_{\max }-K_{\mathrm{op}}$. In the following, the onset of

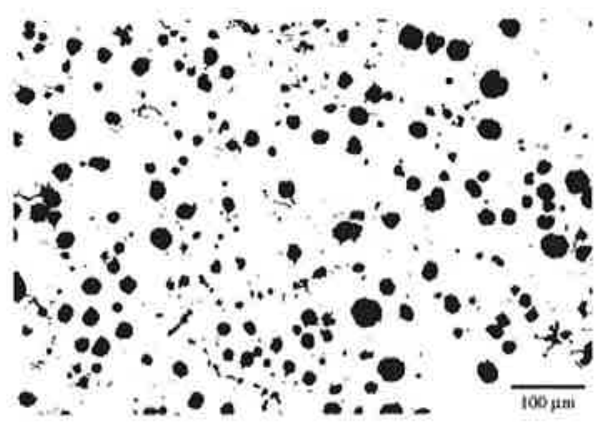

(a)

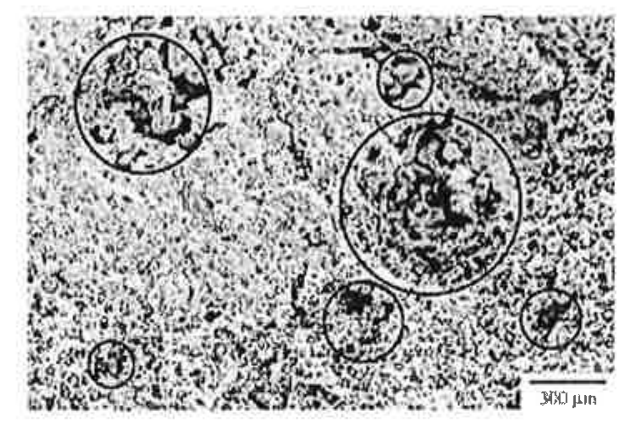

(b)

Fig. 1. Microscopic observations of a fractured surface of an SG cast iron specimen submitted to highcycle fatigue tension/tension test: (a) graphite nodules; (b) microshrinkage cavities. 
microcrack propagation is described by a criterion postulated by Pellas et al. [14]

$$
\Delta K_{\text {eff }}=g(R) K_{\max }-K_{\text {th }}(a) \geqslant 0
$$

where $K_{\text {th }}(a)$ is a function of the current crack size $a$ [15]. The function $g$ models the influence of load ratio $R$.

In many practical situations, it can be assumed that the flaw size is bounded by a maximum value $a_{\mathrm{M}}$. In the case of cyclic loading, a cyclic threshold stress can be defined as the lowest value of the stress level below which no failure occurs (i.e. the failure probability is equal to zero). The cyclic threshold stress, $S_{\mathrm{th}}$, is related to the threshold stress intensity factor $K_{\mathrm{th}}$. Its expression, when $g(R)=1$, can be derived from Eqs (1) and (2)

$$
S_{\mathrm{th}}\left(a_{\mathrm{M}}\right)=\frac{K_{\mathrm{th}}\left(a_{\mathrm{M}}\right)}{Y \sqrt{a_{\mathrm{M}}}}
$$

The results derived so far will be used to study high-cycle fatigue of SG cast iron. It is assumed that the microcrack propagation law is a modified version of an Elber law [13], and keeps the main features of the macrocrack propagation law based upon the generalized Paris' law proposed by Pellas et al. [14]

$$
\frac{\mathrm{d} a}{\mathrm{~d} N}=C\left[\frac{K_{\max } g(R)-K_{\mathrm{th}}(a)}{K_{\mathrm{c}}-\frac{K_{\mathrm{th}}(a)}{g(R)}}\right]^{n}
$$

This law has the advantage of a reasonable description of the near-threshold crack propagation rate: this is a key feature in the present case. In high-cycle fatigue, during the majority of cycles leading to failure, the flaw size does not grow significantly. Therefore, it is assumed that the evolution of the threshold stress intensity factor $K_{\text {th }}$ is only dependent on the initial flaw size $a_{0}$. Furthermore, the flaw size usually varies between 10 and $500 \mu \mathrm{m}$, a value for which $K_{\text {th }}$ is only weakly dependent upon $a_{0}$ [15]. Hence, as a first approximation, the threshold stress intensity factor $K_{\text {th }}$ will be taken as a constant. This hypothesis is consistent with experimental data obtained on SG cast iron (see below). The following closed-form solution can be derived by integration of Eq. (4)

$$
\varphi\left(\sqrt{\frac{a_{\mathrm{c}}}{a_{\mathrm{M}}}}\right)-\varphi\left(\sqrt{\frac{a_{\mathrm{c} 0}}{a_{\mathrm{M}}}}\right)=C^{*}\left[\frac{g(R) K_{\mathrm{th}}}{K_{\mathrm{c}}-\frac{K_{\mathrm{th}}}{g(R)}}\right]^{n}\left(\frac{\sigma_{\mathrm{max}}}{S_{\mathrm{th}}}\right)^{n} N_{\mathrm{F}}
$$

where $a_{\mathrm{c} 0}$ denotes the initial flaw size that becomes critical [i.e. equal to $a_{\mathrm{c}}$, such that $K_{\max }\left(a_{\mathrm{c}}\right)=$ $K_{\mathrm{c}}$ ] after $N_{\mathrm{F}}$ cycles. The constant $C^{*}$ is equal to $C / a_{\mathrm{M}}$. The value of the function $\varphi$ depends upon the power $n$ of the microcrack propagation law

$$
\begin{array}{cc}
\varphi(x)=2 \frac{\left(x-x_{\mathrm{th}}\right)^{1-n}\left[x_{\mathrm{th}}-(n-1) x\right]}{(n-1)(n-2)} & \text { when } n \neq 1 \text { and } n \neq 2 \\
\varphi(x)=2\left[x+x_{\mathrm{th}} \ln \left(x-x_{\mathrm{th}}\right)\right] & \text { when } n=1 \\
\varphi(x)=2 \ln \left(x-x_{\mathrm{th}}\right)-\frac{2 x}{x-x_{\mathrm{th}}} & \text { when } n=2
\end{array}
$$


where $x_{\mathrm{th}}$ is obtained by using Eqs (1) and (2)

$$
x_{\mathrm{th}}=\sqrt{\frac{a_{\mathrm{th}}}{a_{\mathrm{M}}}}=\frac{S_{\mathrm{th}}}{\sigma_{\max } g(R)}
$$

The aim of the next section is to derive an expression for the cumulative failure probability when the material experiences cyclic loading conditions for which the defects are randomly distributed within the structure and can grow stably.

\section{CUMULATIVE FAILURE PROBABILITY IN TENSION}

In the following, for the sake of simplicity, we shall consider only cases for which the tensile load level, $\sigma_{\max }$ is constant. Initial heterogeneities are assumed to be randomly distributed, and are modelled by a flaw size distribution $f$, which is a function of the size $a$. This function needs to be determined to assess the reliability of heterogeneous materials. The cumulative failure probability $P_{\mathrm{F} 0}$ of an element $\Omega_{0}$ is the probability of finding an initial flaw whose size is larger than the critical flaw size $a_{\mathrm{co}}[16]$

$$
P_{\mathrm{F} 0}=\int_{\mathrm{a}_{\mathrm{co}}}^{+\infty} f_{0}(a) \mathrm{d} a
$$

Equation (10) can be used when the flaw size evolution is deterministic, and if the only flaws to cause failure are those initially present within the material. The cumulative failure probability $P_{\mathrm{F}}$ of a structure $\Omega$ is related to the cumulative failure probability $P_{\mathrm{Fo}}$ in the framework of the weakest link theory [17]. In pure tension or compression, the stress state is uniform and, provided that the flaw size distribution is uniform (i.e. characterized by a unique function $f$ over the whole body), the relationship between the two cumulative failure probabilities is given by

$$
P_{\mathrm{F}}=1-\left(1-P_{\mathrm{F} 0}\right)^{V / V_{0}}
$$

Equation (11) is valid when the flaw interaction can be neglected. In SG cast iron, the average distance between flaws is large compared with their size, so that this hypothesis is very often fulfilled. It is worth noting that in high-cycle fatigue, the propagation stage on a macroscopic scale tends to become negligible when compared, in terms of number of cycles, to the micropropagation stage. In such circumstances, Eq. (11) can be applied to both brittle and ductile materials in highcycle fatigue. Since the propagation stage is neglected when Eq. (11) is used, this equation corresponds to a lower bound to the cumulative failure probability of the structure. Hence, in the following, failure refers to local failure, i.e. macroscopic initiation, which is a conservative estimate of the structural failure.

In the next section, an identification procedure of the propagation law is proposed and applied to fatigue experiments performed on SG cast iron specimens. An experimental identification of the flaw distribution is performed on the same specimens.

\section{ANALYSIS OF FATIGUE TESTS ON SG CAST IRON}

In this section, a series of tension/compression experiments performed at LMT-Cachan and Renault are analysed in detail. These experiments have been carried out at different stress levels on specimens made of ferritic SG cast iron containing less than $5 \%$ pearlite. The mechanical properties are the following: $\sigma_{\mathrm{y} 0.2 \%}=350 \mathrm{MPa}, \sigma_{\mathrm{u}}=510 \mathrm{MPa}, \mathrm{HV}_{30}=185$ and $E=185 \mathrm{GPa}$. The ratio between the threshold stress intensity factor and the critical stress intensity factor is of the 
order of $1 / 3$ [15]. Cylindrical specimens ( $8 \mathrm{~mm}$ in diameter) are tested under cyclic tension with two different load ratios $(R=-1$ and 0.1$)$.

Each curve in an $S-N$ plot corresponds to a constant failure probability. It can be shown from Eqs (10) and (11) that a constant failure probability can be rewritten in tension/compression as

$$
\frac{a_{\mathrm{c} 0}}{a_{\mathrm{M}}}=b\left(P_{\mathrm{F}}\right)
$$

where the constant $b$ depends upon the details of the flaw distribution and the value of the considered cumulative failure probability. By using Eqs (5) and (12), the number of cycles to failure is given by

$$
\begin{gathered}
N_{\mathrm{F}}=+\infty \quad \text { if } \sigma_{\max } g(R) \sqrt{b} \leqslant S_{\mathrm{th}} \\
N_{\mathrm{F}}=\left[\frac{K_{\mathrm{c}}-\frac{K_{\mathrm{th}}}{g(R)}}{K_{\mathrm{th}} g(R)}\right]^{n}\left(\frac{\sigma}{S_{\mathrm{th}}}\right)^{-n}\left[\varphi\left(\frac{S_{\mathrm{th}} K_{\mathrm{c}}}{\sigma_{\max } K_{\mathrm{th}}}\right)-\varphi(\sqrt{b})\right] \text { if } \sigma_{\text {max }} g(R) \sqrt{b}>S_{\mathrm{th}}
\end{gathered}
$$

Equation (13) corresponds to a case where no failure at all is possible and the limting stress case $\sigma_{\max } g(R) \sqrt{b}=S_{\text {th }}$ corresponds to the "fatigue limit" for a given cumulative failure probability. The expression for the cumulative failure probability then only depends upon the initial flaw distribution and the value of the cyclic threshold stress $S_{\mathrm{th}}$. This case can allow an identification of the threshold stress $S_{\text {th }}$ and the flaw size distribution independently of the crack growth law [18]. Equation (14) corresponds to higher stress states where fatigue failure occurs. For a given value of $b$ (i.e. a given failure probability), the evolution of the number of cycles to failure mainly depends on the crack growth law. Therefore, the analysis of a constant failure probability enables us to identify the parameters of the crack growth law, provided the flaw size distribution is known (i.e. the different values of the constant $b$ have been identified).

Lastly, it is assumed that the flaw size distribution $f_{0}$ can be modelled by a beta function

$$
f_{0}(a)=\frac{a^{\alpha-1}\left(a_{\mathrm{M}}-a\right)^{\beta-1}}{B_{\alpha \beta} a_{\mathrm{M}}^{\alpha+\beta-1}} \quad \text { when } 0<a<_{\mathrm{M}}, \quad \alpha>0, \quad \beta>0
$$

This distribution possesses the key property of being bounded by 0 and $a_{\mathrm{M}}$. In the present case, the only defects to be considered are microshrinkage cavities whose maximum size is given by the minimum detectable size by NDE techniques.

In the following, the flaw size distribution $f$ and the microcrack propagation law parameters, $C, n, m$ will be experimentally identified from the tests performed for a load ratio $R=0.1$. Systematic microscopic observations of the fractured surfaces of 50 specimens subjected to high-cycle fatigue tension/tension tests were performed by using a Scanning Electron Microscope to determine the initial flaw distribution. The initial defects on the fractured surfaces can be distinguished with no difficulty since the stable propagation area has different morphological characteristics as compared to those of the initial defects. Pictures of the fractured surfaces were stored in a SUN workstation and an image analysis program was used to determine the defect distribution. The size of the flaw is defined as the diameter of the smallest circle in which the flaw may be included [Fig. 1(b)]. Flaws with a diameter less than $80 \mu \mathrm{m}$ were not considered to avoid confusion with graphite nodules (with maximum size of the order of $60 \mu \mathrm{m}$ in diameter). Since pores of small size $(a<30 \mu \mathrm{m})$ do not exist in the structure, we make the hypothesis that the probability of finding a defect of size equal to zero is zero. By taking into account this hypothesis, the parameters of the experimental 
flaw distribution $\alpha$ and $\beta$ are identified. The following values are oblained: $\alpha=2.3, \beta=18$, and the value chosen for $a_{\mathrm{M}}$ is $400 \mu \mathrm{m}$. This result shows that we are dealing wilh short cracks, and that the threshold stress intensity factor can be considered as a constant for flaws of this size, as shown in Ref. [19],

It is assumed that $V V_{0}$ is equal to 1 since the size of the specimens is small: $8 \mathrm{~mm}$ in diameter compared to $a_{\mathrm{Y}}=400 \mu \mathrm{m}$. The value of the threshold stress can then be deduced from $\mathrm{Eg}$. (3) by assuming that $Y \cong 2$ and $K_{\mathrm{th}}=4.2 \mathrm{MPal} \sqrt{\mathrm{m}}[19], S_{\mathrm{th}}=105 \mathrm{MPa}$. Figure 2 shows the identilied flaw distribution. The values of flaw size corresponding to a failure probability of 10,50 and $90 \%$ are depicted in the same figure and given in Table 1 . For a failure probability of $90 \%$, the critical flaw size has the same order of magnitude as the maximum size of nodular graphite.

The second step of the identification is concerned with the parameters of the microcrack propagation law. Since the $S-N$ curves used for the identification are obtained in tension, this identification is straightforward: it consists of the analysis of the constant cumulative failure probability $P_{\mathrm{F}}=50 \%$ [i.e. $a_{\mathrm{c} 0}=$ constant, see Eq. (12)]. This failure probability is defined such that it minimizes the following error

$$
\operatorname{Err}=\frac{1}{n_{\mathrm{e}}} \sum_{i=1}^{n_{\mathrm{c}}}\left[N_{\text {Fie }}-N_{\mathrm{Fi}}\left\{b\left(P_{\mathrm{F}}=50 \%\right), \frac{\sigma_{\mathrm{max}}}{S_{\mathrm{th}}}, n, C^{*}, R=0.1\right\}\right]^{2}
$$

where $N_{\mathrm{Fi}}$ is the number of cycles to failure predicted according to Eq. (14). It can be noticed that Eq. (16) corresponds to the assunption that the mean value of the number of cycles to failure experimentally measured for a given stress level coincides with a cumulative failure probability of $50 \%$. Although this assumption is not fully consistent with other assumptions made to develop the approacl discussed herein, it can be considered as a reasonable approximation.

An expression for the function $g$ has been proposed by Pellas et al. [14]

$$
g(R)=\frac{1-R}{1-m R}
$$

where $m$ is a material parameter. The values of $m$ are usually of the order of 0.5 . The approximation $g(R)=\cong 1$ can be used when $R=0.1$. The identification of the propagation law gives the following values: $n=2$ and $C^{*}=5.9 \times 10^{-5}$. In Fig. 3 , the cumulative failure probabilities $P_{\mathrm{F}}=10 \%$,

Table 1. Values of the constant $b$ for SG cast iron

\begin{tabular}{cc}
$\begin{array}{c}\text { Failure probability } \\
(\%)\end{array}$ & Constant $h$ \\
\hline 10 & 0.06 \\
50 & 0.14 \\
90 & 0.25 \\
\hline
\end{tabular}

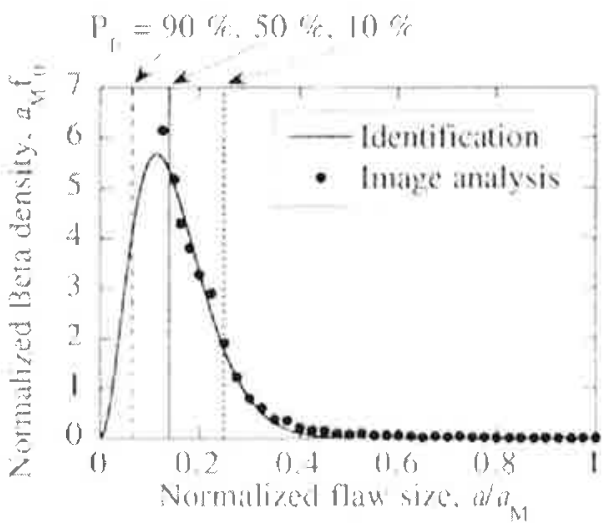

Fig. 2. Identification of the initial flaw distribution of $\mathrm{SO}$ cast iron from image analysis 


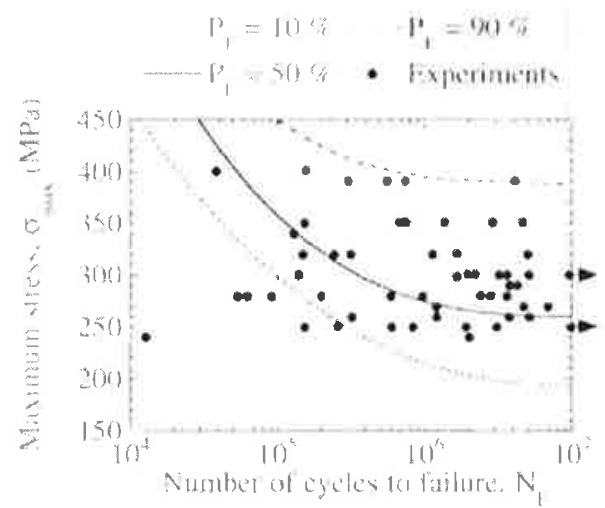

Fig. 3. Predicted failure probabilities compared wilh expcriments for $R=0.1$.

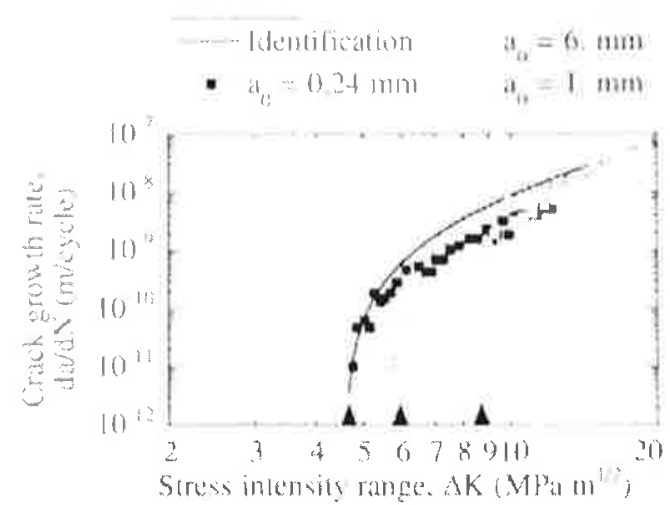

Fig. 4. Crack growth rate as a lunction of stress intensity range for $R=0.1$

$P_{\mathrm{F}}=50 \%$ and $P_{\mathrm{F}}=90 \%$ are plotted with the experimental results. It is assumed that the number of experiments is large enough to properly evaluate the failure probabilities $10 \%$ and $90 \%$. This figure shows that most experimental data lie between the two failure probabilities $P_{\mathrm{F}}=10 \%$ and $P_{\mathrm{F}}=90 \%$. Experimental observations of specimens where the corresponding point in the curve $S-N$ is outside the zone between the failure probabilities $P_{\mathrm{F}}=10 \%$ and $P_{\mathrm{F}}=90 \%$ show that these specimens contain flaws larger than $a_{\mathrm{M}}$. Had such flaws been present in industrial cast components, they would have been detected by using NDE techniques.

Figure 4 shows the crack growth rate as a function of the stress intensity amplitude. The solid curve is identified from the analysis of a constant failure probability. The other points represent experimental results obtained on specimens made of SG cast iron. The solid squares concern an artificial short crack of initial length $a_{0}=240 \mu \mathrm{m}$ [20]. The open circles correspond to an artificial crack of initial length $a_{0}=1 \mathrm{~mm}$. The open squares concern an artificial long crack of initial length $a_{0}=6 \mathrm{~mm}$ [20]. The identified curve is in good agreement with the experimental results, especially for short cracks in the near-threshold regime. The discrepancy with the results for long cracks can be described by threshold differences.

The last parameter to be identified is $m$ to model the load ratio effect [see Eq. (17)]. By comparing two faligue limits (for $R=-1$ and 0.1 ) for the same available cumulative failure probability $(50 \%)$, the parameter $m$ is cletermined by using Eq. (13)

$$
\sigma_{\infty}\left(P_{\mathrm{F}}=50 \%, R=0.1\right) g(0.1)=\sigma_{\infty}\left(P_{\mathrm{F}}=50 \%, R=-1\right) g(-1)
$$

The identified value is $m=0.59$. Figure 5 shows the cumulative failure probabilities $P_{\mathrm{F}}=10 \%$, $P_{\mathrm{F}}=50 \%$ and $P_{\mathrm{r}}=90 \%$, and the experimental results for $R=-1$. The same type of conclusion can be drawn for $R=-1$ as for $R=0.1$. This result shows that the function $g$ accounts for the influence of load ratio for different cumulative failure probabilities. All the material parameters identified for the material studied herein are gathered in Table 2.

\section{CONCLUSIONS}

A reliability analysis taking account of flaw size distributions has been developed for components subjected to cyclic loading conditions. Therefore, the underlying hypothesis is that the scatter in failure stress and number of cycles is entirely attributed to the random distribution of flaws. 
Table 2. Material parameters modelling lijgh-cycle fatigue of SG cast iron

\begin{tabular}{cc}
\hline Parameter & Value (unit) \\
\hline$a_{\mathrm{M}}$ & $400 \mu \mathrm{m}$ \\
$Y^{\prime}$ & 2 \\
$S_{\mathrm{th}}$ & $105 \mathrm{MPa}$ \\
$\lambda$ & 2.3 \\
$\beta$ & 18 \\
$k$ & 0.33 \\
$C^{*}$ & $5.9 \times 10^{-3}$ \\
$n$ & 2.0 \\
$m$ & 0.59 \\
\hline
\end{tabular}

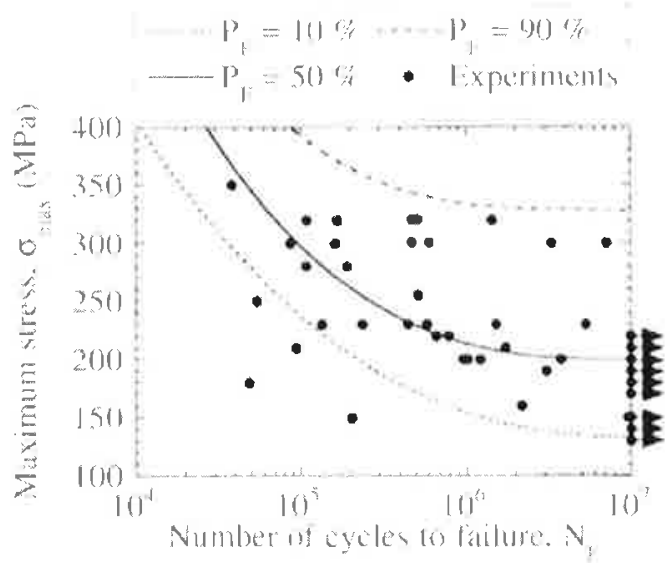

Fig. 5. Predicted lailure probabilities compared with cxperiments for $R=1$.

Emphasis is also put on the micro-propagation stage, which is directly related to the evolution of initial flaws. An expression for the cumulative failure probability is detived in the framework of the weakest link theory and by assuming that the flaw interaction can be neglected. The study is applied to SG cast iron, where the maximum defect size is of the order of $400 \mu \mathrm{m}$. The crack propagation law is based on a modified Paris' law for this kind of flaw. 'The threshold stress intensity factor, which is dependent upon the current size of defect, is considered as a material constant for the described SG cast iron. A simplified expression for the cumulative failure probability is derived for cyclic failure in the case of tension. The analysis of a constant failure probability allows us to identily the parameters of the microcrack propagation law.

Experimental data on SG cast iron $i n$ tension are analysed within this framework for experiments with a load ratio $R=0.1$. It is assumed that the flaw distribution is described by a beta probability density function. The flaw distribution is identified experimentally by using SEM observations and image analysis. The predictions of the failure probabilities for the two series of data $(R=0.1$ and $R=-1$ ) are in good agrecment with the experimental number of cycles to failure. This result shows that the inflaenee of the load ratio is reasonably described by the model. Finally, the identified crack growth rate as a function of the stress intensity factor is in good agreement with experimental results, which indicates that the threshold stress intensity factor can be considered as a constant for small cracks. These results show that the expression for the cumulative failure probability proposed herein is able to model fatigue data obtained on SG cast iron. Extension to heterogencous stress fields (c.g. bending) are under way to evaluate the predictive capabilities of the model.

Arknowledgenents-H.Y.A., R.B. and F.H. gratefully ackmowledge the financial support of Renault through contract CNRS/109 (H5-24-12) with LMT-Cachan.

\section{REFERENCES}

1. J. Le Gal (1994) Trends and metallurgical factors involved in automotive cast iron parts. In: Physical Metallurgy of Cast Iron (Edited by V. Cr. Lesoult and J. Lacize). Advanced Materials Rese'trch Volumes 4-5, Scitec Publications, Zürich, Switzerland, 129-136.

2. W. Wcibull (1939) A statistical theory of the strength of matcrials. Roy. Swed. Inst. Eng. Res. 151.

3. S. B. Batdorf and J. G. Crose (1974) A statistical theory for the fracture of brittle structures subjected to polyaxial stress states. ASME J. Appl. Mech. 41, 459-465. 
4. A. G. Evans (1978) A general approach for the statistical analysis of multiaxial fracture. J. Am. Ceram. Soc. 61, 302-308.

5. J. Lamon and A. G. Evans (1983) Statistical analysis of bending strengths for brittle solids: a multiaxial fracture problem. J. Am. Ceram. Soc. 66, 177-182.

6. J. Lamon (1988) Statistical approaches to failure for ceramic reliability assessment. J. Am. Ceram. Soc. $71,106-112$

7. K. Sobczyk (1986) Modelling of random fatigue crack growth. Engng Fract. Mech. 24, 609-623.

8. A. de S. Jayatilaka and K. Trustrum (1977) Statistical approach to brittle fracture. J. Mater. Sci. 12, $1426-1430$.

9. F. Hild and D. Marquis (1992) A statistical approach to the rupture of brittle materials. Eur. J. Mech., A/Solids 11, 753-765.

10. K. J. Miller (1982) The short crack problem. Fatigue Fract. Engng Mater. Struct. 5, 223-232.

11. D. Taylor and J. F. Knott (1982) Growth of fatigue cracks from casting defects in nickel-aluminium bronze. Met. Tech. 9, 221-228.

12. J.-L. Bréat, F. Mudry and A. Pineau (1983) Short crack propagation and closure effects in a 508 steel. Fatigue Fract. Engng Mat. Struct. 6, 349-358.

13. W. Elber (1971) The significance of fatigue crack closure. In: Damage Tolerance in Aircraft Structures, ASTM, Philadelphia, PA, USA, STP 486, 230-242.

14. J. Pellas, G. Baudin and M. Robert (1977) Mesure et calcul du seuil de fissuration après surcharge. Recherche aérospatiale 3, 191-201.

15. P. Clément, J.-P. Angeli and A. Pineau (1984) Short crack behavior in nodular cast iron. Fatigue Fract. Engng Mater. Struct. 7, 251-265.

16. F. Hild and S. Roux (1991) Fatigue initiation in heterogeneous brittle materials. Mech. Res. Commun. 18, 409-414.

17. A. M. Freudenthal (1968) Statistical approach to brittle fracture. In: Fracture (Edited by H. Liebowitz), Academic Press, New York, NY, USA, Vol. 2, 591-619.

18. H. Yaacoub Agha, A.-S. Béranger, R. Billardon and F. Hild (1997) Statistical damage tolerance for cast iron under fatigue loadings. In: Proceedings Third International Conference on Material Processing Defects (Edited by M. Predeleanu and P. Gilormini), Elsevier, Amsterdam, The Netherlands, 415-424.

19. P. Clément and A. Pineau (1984) Amorçage et propagation de petites fissures dans la fonte à graphite spheroïdal. In: Proceedings Journées internationales de printemps de la SFM, SFM, Paris, France, 203-218.

20. P. Clément (1984) Propagation par fatigue de petits défauts dans une fonte GS. CNAM report, CNAM Paris. 